including but not confined to vulnerable groups of patients, or within the population?

- Have you experienced any particular legislative barriers or enablers in relation to parity, beyond health legislation? (Examples might include welfare reform, the criminal justice system, education, immigration and asylum.)

- From your perspective, what does 'good' look like? (For example, people with mental health disorders would have the same physical health outcomes as people without them.)

- What are the organisational barriers and enablers, whether in local government or in your part of the healthcare system?

- What, in your view, are the financial, cultural, structural, educational (undergraduate/postgraduate/continuing professional development, etc.) and technological implications of delivering parity of esteem for mental health?

Please address your responses to Greg Smith (gsmith@rcpsych.ac.uk). Together we can make a difference.

\section{References}

Bailey, S., Gerada, C., Lester, H., et al (2012) The cardiovascular health of young people with severe mental illness: addressing an epidemic within an epidemic. Psychiatrist, 36, 375-378.

Bailey, S., Thorpe, L. \& Smith, G. (2013) Whole-Person Care: From Rhetoric to Reality. Achieving Parity Between Mental and Physical Health (Occasional Paper OP88). Royal College of Psychiatrists. Curtice, M. J. \& Exworthy, T. P. (2010) FREDA: a human rightsbased approach to healthcare. Psychiatrist, 34, 150-156. Department of Health (2011) National expenditure data 2003-04 to 2010-11. Available at https://www.gov.uk/government/uploads/ system/uploads/attachment_data/file/156133/dh_131856.xls.xls (accessed July 2013)

Fritz, G. K. \& Kennedy, P. J. (2012) The long road ahead to mental health parity. Journal of the American Academy of Child and Adolescent Psychiatry, 51, 458-460.

Ganju, V. (2012) Non-communicable diseases and the menta health gap: what is to be done? International Psychiatry, 9, 79-80. Garrett, L., Chowdhury, A. M. R., Pablos-Méndez, A. (2009) All for universal health coverage. Lancet, 374, 1294-1299.

Kessler, R. C., Amminger, G. P., Aguilar-Gaxiola, S., et al (2007) Age of onset of mental disorders: a review of recent literature. Current Opinion in Psychiatry, 20, 359-364.

Kim-Cohen, J., Caspi, A., Moffitt, T. E., et al (2003) Prior juvenile diagnosis in adults with mental disorder: developmental follow-back of a prospective longitudinal cohort. Archives of General Psychiatry, $60,709-717$.
Knapp, M., McDaid, D. \& Parsonage, M. (2011) Mental Health Promotion and Mental Illness Prevention: The Economic Case. Department of Health.

Lasalvia, A., Zoppei, S., Van Bortel, T., et al (2013) Global pattern of experienced and anticipated discrimination reported by people with major depressive disorder: a cross-sectional survey. Lancet, 381, 55-62.

McManus, S., Meltzer, H., Brugha, T., et al (2009) Adult Psychiatric Morbidity in England, 2007. Results of a Household Survey. Health and Social Information Centre, Social Care Statistics.

McManus, S., Meltzer, H. \& Campion, J. (2010) Cigarette Smoking and Mental Health in England: Data from the Adult Psychiatric Morbidity Survey. National Centre for Social Research.

Ormel, J., Petukhova, M., Chatterji, S., et al (2008) Disability and treatment of specific mental and physical disorders across the world. British Journal of Psychiatry, 192, 368-375.

Pettigrew, T. F. \& Tropp, L. R. (2006) A meta-analytic test of intergroup contact theory. Journal of Personal and Social Psychology, 90, 751-783.

Phelan, M., Stradins, L. \& Morrison, S. (2001) Physical health of people with severe mental illness. BMJ, 322, 443-444.

Shiers, D. \& Kendall, T. (2012) Tackling a scandal of premature mortality; time for a 'hearts \& minds' approach. LSE Health and Social Care blog, 6 July, http://blogs.Ise.ac.uk/ healthandsocialcare/2012/07/06/tackling-a-scandal-of-prematuremortality-time-for-a-hearts-minds-approach/ (accessed July 2013).

Siru, R., Hulse, G. K. \& Tait, R. J. (2009) Assessing motivation to quit smoking in people with mental illness: a review. Addiction, 104 719-733.

Sterne, L. (1761) The Life and Opinions of Tristram Shandy, Gentleman (eds M. New \& J. New), vol. 3, ch. 4. University of Florida Press $(1978)$

Thornicroft, G. (2008) Stigma and discrimination limit access to mental health care. Epidemiologica e Psichiatrica Sociale, 17, $14-19$

Thornicroft, G. (2011) Physical health disparities and mental illness: the scandal of premature mortality. British Journal of Psychiatry $199,441-442$

UK Clinical Research Collaboration (2006) UK Health Research Analysis. UKCRC.

United Nations (2009) Concluding Observations of the Committe on Economic Social and Cultural Rights: United Kingdom of Great Britain and Northern Ireland, the Crown Dependencies and the Overseas Dependent Territories. UN.

Wittchen, H. U., Jacobi, F., Rehm, J., et al (2011) The size and burden of mental disorders and other disorders of the brain in Europe 2010. European Neuropsychopharmacology, 21, 655-679.

World Health Assembly (2012) Ninth plenary meeting, 25 May 2012. WHA65.4. Agenda item 13. Available at http://www who. int/mental_health/WHA65.4_resolution.pdf (accessed June 2013).

World Health Organization (2004) Death and DALY Estimates for 2004 by Cause for WHO Member States. WHO. Available at http:// www.who.int/healthinfo/global_burden_disease/estimates_country/ en/index.html (accessed June 2013).

THEMATIC PAPERS

Behavioural and Brain Sciences Unit, Institute of Child Health, London, UK, email d.skuse@ ucl.ac.uk

\title{
Conflict and mental health in North Africa and the Middle East
}

\author{
David Skuse
}

Conflict in the Middle East and in North Africa has consistently made headlines over the past 2 years for one reason or another. Yet despite the extensive coverage of slaughter and mayhem, little has been said about the destruction of the infrastructure supporting medical services, and even less about the psychiatric consequences of conflict. There is growing evidence of deteriorating mental health of the general population in affected countries, among both those who stay and the burgeoning 
refugee diaspora. Even worse, in some ways, is the abandonment (or even the targeting) of psychiatric patients, whose hospitals have been destroyed and whose carers have long since fled. In this issue we review the crisis in three countries affected by civil war: Libya, Syria and the Sudan.

Libya went through a convulsive, although relatively brief, civil war that began in February 2011 and ended in October of that year. As Dr Abuazza writes, decades of neglect had left the mental health system in that country in bad shape. There are now just two functioning psychiatric hospitals. The impact of the civil war was to drive many doctors out of the country and few mental health professionals remained to cope with patients. Although matters are beginning to turn around for the better, those seeking help have not only overwhelmed services in those hospitals but they have spilled over into neighbouring countries too, such as Egypt.

Drs Abou-Saleh and Mobayed report on the conflict in Syria, a situation that has persisted now since March 2011 and shows no sign of abating.
General medical care has suffered terribly. The authors report that children in particular are affected, because armed groups (especially government forces) have specifically targeted them. Post-traumatic stress disorder (PTSD) could be a problem for up to $60 \%$ of adults and an even higher proportion of children. Active destruction of psychiatric facilities has been witnessed.

Finally, Drs Ali, Saeed and Sultan give us an account of the outcome of 22 years or more of conflict in Sudan, where the effects of civil war have been compounded by famine. The proportion of the population affected by PTSD is similar to that in Syria, studies suggest, but in other respects the situation differs from that in Middle Eastern states, perhaps especially in the south. There is a cultural reluctance to acknowledge the extent of mental health problems, because of the stigma. Spiritual healers still play a major role. Yet, as in Libya and Syria, there is a growing call for help from the international community to provide mental health management, both to those within the country and to the refugee populations across borders.

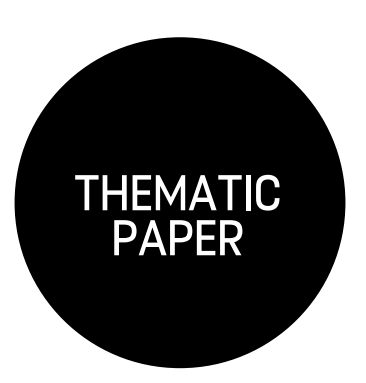

\title{
CONFLICT AND MENTAL HEALTH IN NORTH AFRICA AND THE MIDDLE EAST
}

\section{The Arab Spring movement:} a catalyst for reform at the psychiatric hospital in Tripoli, Libya

\author{
Adel Abuazza
}

Consultant Psychiatrist and General Director, Al Razi Hospital, Tripoli, Libya,

email adelabuazza@yahoo.ie

The assistance of Dr Fahmy Bahjat, mental health Bahjat, mental health
consultant to the World Health Organization mission in Libya, in the preparation of this paper is gratefully acknowledged.
Decades of neglect have left the mental health system in Libya in bad shape. Services for the entire population are scarce, highly centralised and provided only through two psychiatric hospitals in the two biggest cities of the country. There are virtually no other mental health services anywhere else in Libya. Even the most basic of services, such as the availability of psychotropic medication for people with severe mental illness, are scarce outside Tripoli and Benghazi. This paper reviews the state of the country's mental health services since the civil war of 2011 and highlights a new fourfold approach taken by the management of the psychiatric hospital in Tripoli.

A major problem faced in Libya in relation to the country's mental health services is that the two main psychiatric hospitals, in Tripoli and Benghazi, have their own limitations, especially a shortage of doctors. This shortage has arisen largely because, during their medical training, students in Libya no longer receive education in psychiatry as part of their curriculum; there are various reasons for this situation in different universities across the country. Also, there is no postgraduate training scheme for psychiatry as a specialty. This lack of an infrastructure for psychiatry as a specialty discourages graduates from working in the field as trainees or consultants. Unfortunately, psychiatric nurses, psychologists and social workers are in no better position. There are no specialist training programmes and they receive no clinical training as part of their education. All these limitations have contributed to a situation in which there are very limited human resources and service provision in mental health.

The lack of psychiatric care was a challenge even before the liberation of Tripoli in 2011. During the 